\title{
Tribenuron methyl exposure inhibits oogenesis in zebrafish Danio rerio (Hamilton, 1822)
}

\author{
C. AKBULUT, B. OZTURK, A. UZUN AND N. D. YON \\ Department of Biology, Sakarya University Serdivan - 54050, Sakarya, Turkey \\ e-mail:ndyon@sakarya.edu.tr
}

\begin{abstract}
Tribenuron methyl is a herbicide that is used to control annual and perennial dicots in cereals and fallow land. Pesticides can access aquatic ecosystems via groundwater and affect water quality and aquatic life. Our study evaluated histopathological effects of tribenuron methyl on ovary of the zebrafish Danio rerio (Hamilton, 1822). Ovary of the fishes in control group not exposed to the herbicide showed normal histological architecture. In the fishes exposed to tribenuron methyl, vacuolisation, edema and dysmorphism were recorded. Significant decrease in the number of primary and mature oocytes as well as dose dependent increase in the number of atretic oocytes were recorded in fishes exposed to tribenuron methyl.
\end{abstract}

Keywords: Herbicide, Histology, Ovary, Tribenuron methyl, Zebrafish

Pesticides are used in agriculture to control weeds, insects and plant diseases. They are introduced into the aquatic environment via agricultural run off, industrial effluents and other sources and lead to undesirable side effects on aquatic life (Baghfalaki et al., 2012). Many pesticides have been reported to be toxic to aquatic organisms (de la Cruz et al., 2014). Pesticides accumulate in organs and tissues of organisms, even when they are present only in small quantities in the environment (Gerber et al., 2016).

Herbicides are generally used in agriculture for protecting plants from fungi or for control of unwanted plants. Herbicides are now widely used on genetically modified crops (Duke and Powles, 2008). As the environment becomes more contaminated by herbicides, the likelihood of aquatic organisms being affected by herbicides will also increase (Rzymski et al., 2013; Annett et al., 2014; Louch et al., 2016)

The toxic effects of herbicides on terrestrial ecosystems and terrestrial animals have been extensively studied. However, there is little information on the toxic effects of herbicides on aquatic animals including fish (Szarek et al., 2000). In toxicity tests, the biological response of aquatic organisms to contaminants serves as direct evidence in determining pollutant effects (Prato et al., 2006; Li et al., 2017).

Tribenuron methyl is a kind of sulfonylurea herbicide and generally used for weed control (Wang et al., 2012) and is widely used in many regions including USA, Canada, Australia, China, Anatolia and Europe. It inhibits the synthesis of amino acids, specifically valine and isoleucine, which prevents cell division and cell growth. It is generally applied as spray and it gets access to soil directly and transferred to the roots. It is a herbicide in category 1 and classified as hazardous to aquatic environment (NCBI, 2017). Sulfonylurea herbicides have very low dosage rates and low acute mammalian toxicity. Some of them have high durability and leaching potential, however there is risk of effects on non-target organisms such as aquatic micro algae and other aquatic organisms (Baghfaaki, 2012). The $96 \mathrm{~h} \mathrm{LC50}$ values of tribenuron methyl for Lepomis macrochirus (bluegill sunfish) and Oncorhynchus mykiss (rainbow trout) have been reported as $>1000 \mathrm{mg} \mathrm{l}^{-1}$ (NCBI, 2017). In the present study, histopathological effects of tribenuron methyl on the ovarian tissue of the zebrafish Danio rerio (Hamilton, 1822) were investigated.

Sexually mature zebrafish (4-5 cm length, 1-2 g weight) were procured from Department of Biology, Sakarya University, Turkey. Individuals were maintained in 201 capacity glass aquaria. Dechlorinated tap water (26-28 ${ }^{\circ} \mathrm{C}$ temperature, $7.7 \mathrm{pH}, 7.9 \mathrm{mg} \mathrm{l}^{-1}$ dissolved oxygen) was used in recirculating chamber. Zebrafish were maintained at $14 \mathrm{~h}$ light $/ 10 \mathrm{~h}$ dark photoperiod. Individuals were fed with artificial diet (Tetramin Pro Energy ${ }^{\circledR}$ ) twice a day. After 7 days of adaptation, fishes were divided into four groups $(\mathrm{n}=10)$ comprising one control and 3 experimental groups, each in triplicates. Experimental groups received sublethal doses of tribenuron methyl (96 h LC50 value $>1000 \mathrm{mg} \mathrm{l}^{-1}$ for fishes; NCBI, 2017) @ $40 \mathrm{mg} \mathrm{l}^{-1}$ (T1), $80 \mathrm{mg} \mathrm{l}^{-1}$ (T2) and $120 \mathrm{mg} \mathrm{l}^{-1}$ (T3) of 
tribenuron methyl for a period of 5 days. On termination of the experiment, fishes were anaesthetised in iced water and ovary tissues were dissected out for histopathological investigations.

The ovarian tissues sampled were fixed in $10 \%$ neutral buffered formalin and processed for routine histology (Yon et al., 2016). During dehydration process, the tissues were passed through ascending series of alcohol. After dehydration process, tissues were cleared in xylene, embedded in paraffin wax and cut into $5 \mu \mathrm{m}$ sections using a microtome (Leica, Germany). The sections were mounted on glass slides, stained with haematoxylin and eosin (H\&E) and the slides were examined under a compund microscope (Leica DM 500).

Ten slides per group were counted and follicles were characterised to understand how tribenuron methyl exposure affect follicular distribution in groups. Statistical analyses were performed by SPSS 15.0. ANOVA with post-hoc Tukey HSD test was applied to determine the distribution of follicle types in control and herbicide exposed groups.

Zebrafish is a well known and widely used vertebrate model organism in development and ecotoxicology studies. There are many advantages with zebrafish which make it a perfect model for toxicological studies viz., easy and cheap maintenance, high fecundity and transparent embryos, short generation time, homology with human genome and adaptability to environmental changes. Histopathological investigations showed no abnormalities in the ovary of the control group fishes. All oocyte stages were observed clearly. Small sized and oval shaped primary oocytes with oval nucleus and plenty of nucleolus were observed at first growth phase (Fig. 1a). Cortical alveoli in the ooplasm were found increased in cortical alveolar stage. It was detected that zona radiata began to form and the follicular epithelium became thicker (Fig. 1a). In vitellogenic phase, oocyte sizes were found increased in comparison to their baseline sizes and larger granular structures were observed. Nutrient (yolk) accumulation and cortical alveoli at periphery of cytoplasm were clear. The vitelline membrane was found to begin development at this stage (Fig. 1b). In maturation phase, oocyte size reached maximum at oogenesis, nuclear membrane was found dissolved and the cytoplasm contained high amount of yolk (Fig. 1a).

In group T1 (40 $\left.\mathrm{mg} \mathrm{l}^{-1}\right)$, vacuolisation was observed at all oocyte stages. Degeneration and decrease in the amount of connective tissues between oocytes were noticed. Atretic oocytes were also present (Fig. 2a). In primary oocytes, contraction was clear at germinal vesicle structure. Some primary oocytes were found to begin transforming to atretic oocytes (Fig. 2b, red square). Dysmorphism at cortical alveolar stage oocytes and shrinking cortical alveolar stage oocytes were observed (Fig. 2c). Opening between follicular epithelium and zona radiata as well as nucleus borders were defined. Structural deterioration at cortical alveoli were noticed. Vacuolisation at cortical alveoli and edema were identified in vitellogenic oocytes (Fig. 2d).

In group T2 (80 $\mathrm{mg} \mathrm{l}^{-1}$ exposure group), dysmorphism was observed at many oocyte stages (Fig. 3a, b, c, d). Contraction of germinal vesicle in some primary oocytes were detected (Fig. 3a) and decrease in the amount of connective tissue between oocytes were identified (Fig. 3a, d). In cortical alveolar stage oocytes, clumping germinal vesicle was located near the periphery (Fig. 3a, b). Degenerated and vacuolated cortical alveoli and edema were observed at cortical alveolar stage

(b)

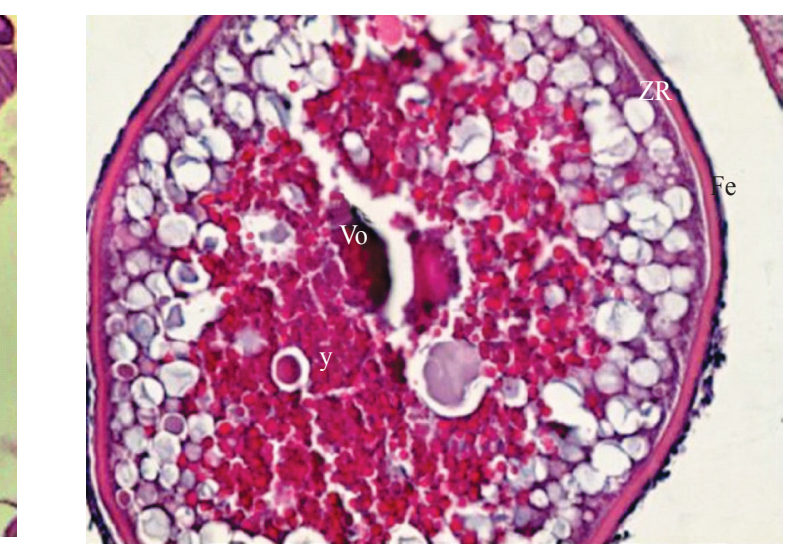

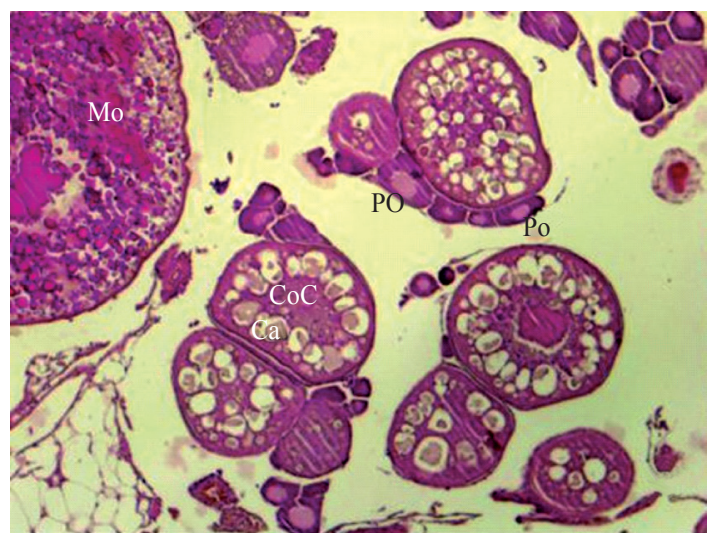

(a)

Fig. 1. Histological sections of ovary of control group fishes, Po: Primary oocyte; Ca: Cortical alveoli, CoC: cortical alveolar stage oocyte, Vo: Vitellogenic oocyte, Mo: Mature oocyte, Y: Yolk granules, ZR: Zona radiata, Fe: Follicular epithelium (H\&E; a: x100, b: x400) 
oocytes. In vitellogenic oocytes disintegration at outward border was noticed (Fig. 3a). Some vitellogenic oocytes were found beginning to transform atretic oocytes and alternations at ooplasm as well as yolk granules were observed (Fig. 3c). In mature oocytes, folding at zona radiata was seen (Fig. 3d).

In ovary of fishes from group T3 $\left(120 \mathrm{mg} \mathrm{l}^{-1}\right.$ exposure group), damages and contraction at germinal vesicle structure of primary ocytes were observed.
Disintegration of zona radiata was observed in cortical alveolar stage oocytes (Fig. 4a). Vacuolated and degenerated cortical alveoli were identified in cortical alveolar stage oocytes (Fig. 4b). Edema was noticed in both cortical alveolar stage and vitellogenic oocytes and opening between zona radiata and vitelline envelope were clearly seen (Fig. 4b, c). Folding at zona radiata structure of mature oocyte was detected. In mature oocytes, deterioration of ooplasm integrity was evident (Fig. 4d).

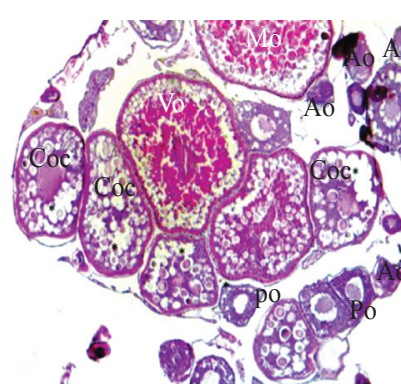

(a)

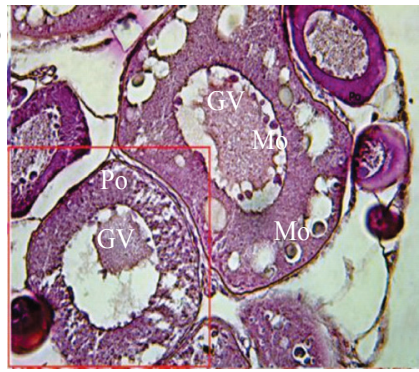

(b)

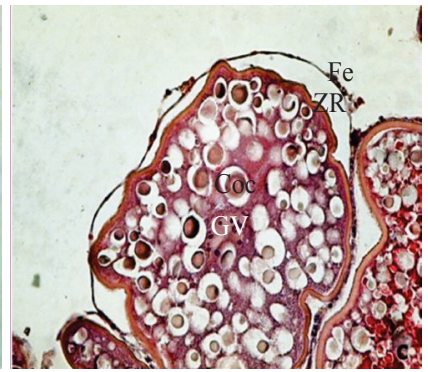

(c)

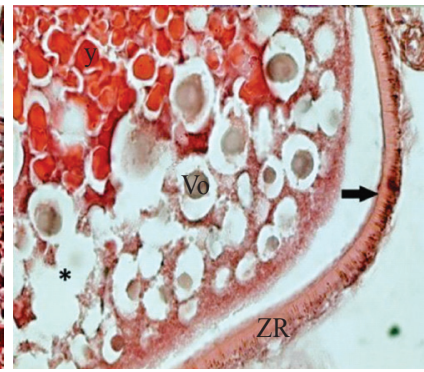

(d)

Fig. 2. Ovary histology of group T1 (40 $\mathrm{mg} \mathrm{l}^{-1}$ tribenuron methyl exposed group), Po: Primary oocyte, CoC: Cortical alveolar stage oocyte, Vo: Vitellogenic oocyte, Mo: Mature oocyte, Ao: Atretic oocytes, GV: Germinal vesicle, No: Nucleolus, ZR: Zona radiata, Fe: Follicular epithelium, ${ }^{*}$ : Vacuolisation, Black arrow: Edema, (H\&E; a: x100, b: x400, c: x400, d: x400)

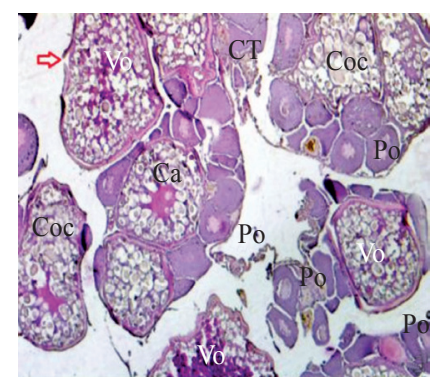

(a)

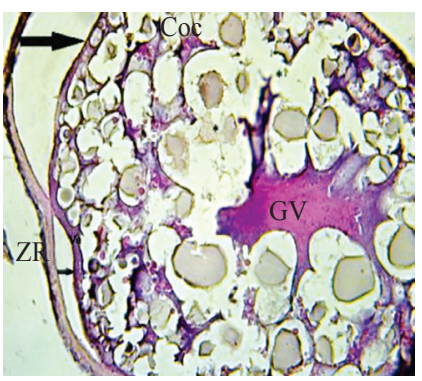

(b)

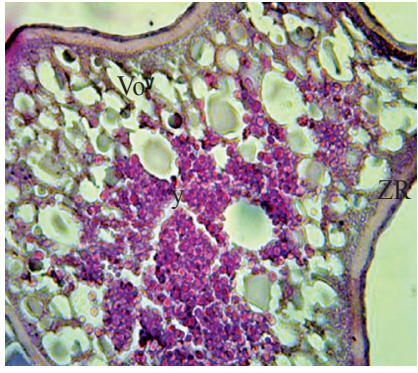

(c)

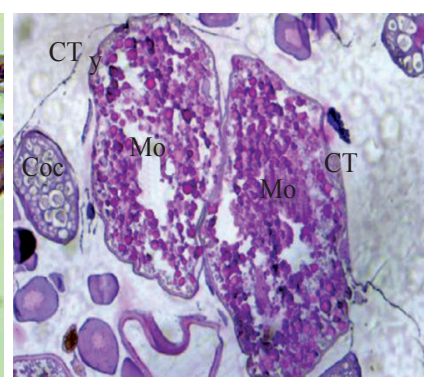

(d)

Fig. 3. Ovary histology of group T3 (80 $\mathrm{mg} \mathrm{l}^{-1}$ tribenuron methyl exposed group), Po: Primary oocytes, CoC: Cortical alveolar stage oocyte, Vo: Vitellogenic oocyte, Mo: Mature oocyte, ZR: Zona radiata, Ve: Vitelline envelope, GV: Germinal vesicle, Ca: Cortical aveoli, CT: Connective tissue, Y: Yolk granules. Black arrow: Edema, Red arrow: Disintegration, >: Contraction of germinal vesicle. (H\&E, a: x100; b: x 400, c: x 400; d: x100)

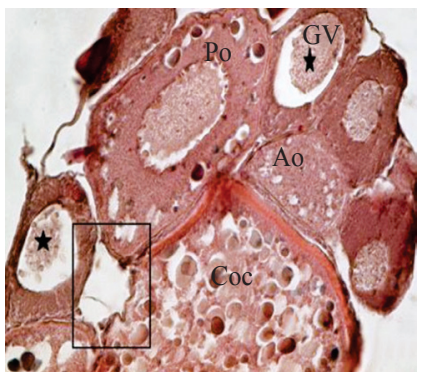

(a)

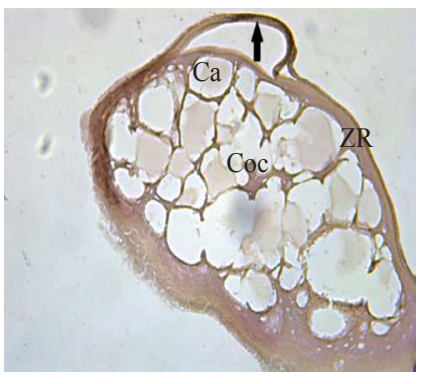

(b)

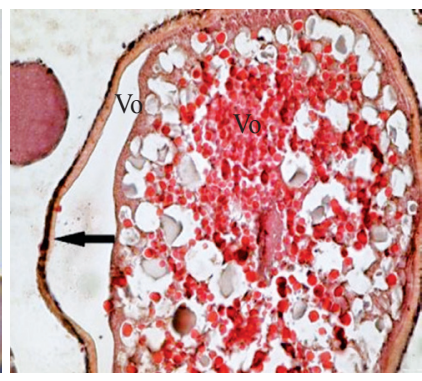

(c)

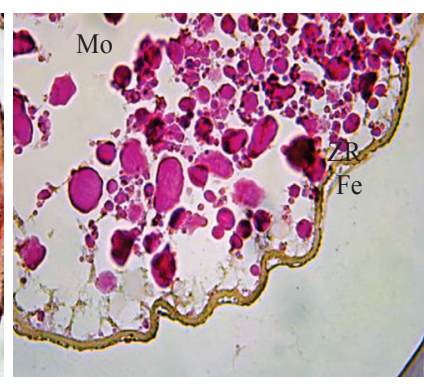

(d)

Fig. 4. Ovary histology of group T3 (120 mg l-1 group), Po: Primary oocytes, CoC: Cortical alveolar stage oocyte, Vo: Vitellogenic oocyte, Mo: Mature oocyte, Ao: Atretic oocyte, ZR: Zona radiata, Ve: Vitelline envelope, GV: Germinal vesicle, Ca: Cortical aveoli, ": Vacuolisation, Black arrow: Edema, Star: Contration of germinal vesicle, Rectangle: Disintegration of zona radiata (H\&E; a: x400; b: x400; c: x400; d: x400) 
Statical analysis indicated that tribenuron methyl exposure caused significant decrease in the number of primary as well as mature oocytes while dose dependent increase in the number of atretic oocytes (Table 1, Fig. 5). Based on these results we concluded that tribenuron methyl exposure slows down oogenesis and inhibits follicle formation (Fig. 5) in zebrafish. consistent with our results. Similarly, Saravanan et al. (2016), reported vacuole formation and increase in the number of immature as well as atretic oocytes in Esomus danricus ovary following cypermetherin exposure.

Dutta and Dalal (2008) studied effects of endosulfan on the ovary of bluegill sunfish. Similar to our study, they

Table 1. Distribution of follicles in control and tribenuron methyl exposed groups (mean $\pm \mathrm{SD}$ )

\begin{tabular}{|c|c|c|c|c|c|}
\hline Treatment group & Primary oocyte & Cortical alveoli & Vitellogenic oocyte & Mature oocyte & Atretic oocyte \\
\hline Control & $141.7 \pm 28.3^{\mathrm{a}^{*}}$ & $6.8 \pm 3.9^{\mathrm{a}^{*}}$ & $19.4 \pm 9.0^{\mathrm{a}^{*}}$ & $33.1 \pm 10.3^{\mathrm{a}^{*}}$ & $3.1 \pm 1.5^{\mathrm{a}^{*}}$ \\
\hline $\mathrm{T} 1$ & $111.3 \pm 27.1^{\mathrm{a}^{*}}$ & $14.2 \pm 3.7^{\mathrm{b}^{*}}$ & $14.2 \pm 6.2^{\mathrm{a}^{*}}$ & $22.7 \pm 6.1^{\mathrm{b}^{*}}$ & $10.9 \pm 4.5^{\mathrm{b}^{*}}$ \\
\hline $\mathrm{T} 2$ & $80.8 \pm 12.1^{\mathrm{b}^{*}}$ & $11.4 \pm 4.7^{\mathrm{b}^{*}}$ & $14.2 \pm 4.4^{\mathrm{a}^{*}}$ & $13.8 \pm 4.4^{\mathrm{c}^{*}}$ & $15.2 \pm 6.5^{\mathrm{bc} *}$ \\
\hline T3 & $65.8 \pm 12.6^{\mathrm{c}^{*}}$ & $10.3 \pm 4.5^{\mathrm{b}^{*}}$ & $15.6 \pm 3.9^{\mathrm{a}^{*}}$ & $9.6 \pm 2.3^{c^{*}}$ & $17.1 \pm 4.1^{\mathrm{c}^{*}}$ \\
\hline
\end{tabular}

*The mean difference is significant at $\mathrm{p}<0.05$. $\mathrm{a}, \mathrm{b}, \mathrm{c}$ ANOVA posthoc test groups

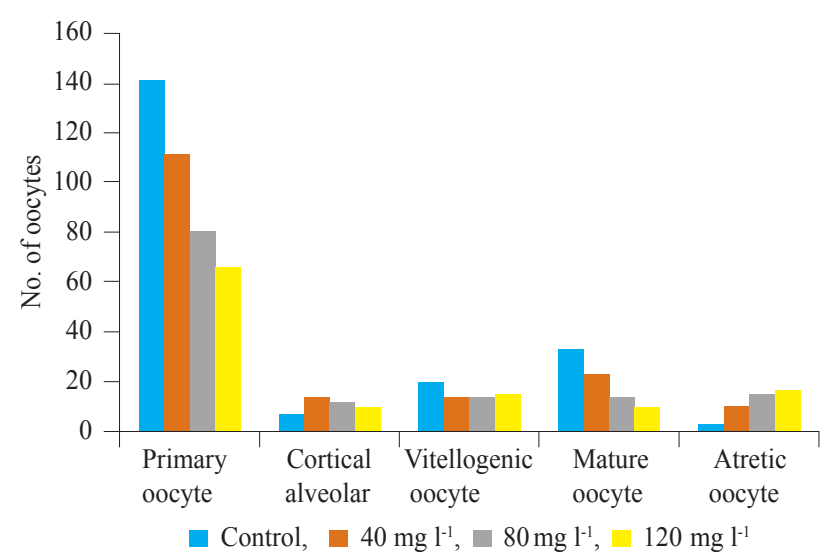

Fig. 5. Follicle stages and number of oocytes at different stages in control and tribenuron methyl exposed groups

Sharma et al. (2017) investigated effects of lead nitrate on Channa striatus ovaries and they detected severe histopathological changes in oocyte and connective tissue structure. Daouk et al. (2011) observed decrease in the number of mature oocytes and an increase in the number of atretic oocytes in zebrafish ovaries after long-term exposure to polychlorinated biphenyls mixtures. They also noticed slight decrease in number of follicles at stage III (vitellogenic) and stage IV (mature oocyte), in comparison with control. These results are consistent with our study. Similarly decrease in the number of different stages of follicles and increase in the number of atretic follicles were observed in our study.

Dutta and Maxwell (2003) studied the effects of diazinon which is an organophosphorous compound on the ovaries of bluegill (Lepomis macrohirus). Sublethal doses of diazinon was found to alter histology of ovary of bluegill. Tantarpale and Rathod (2014) reported histopathological alternations following cypermetherin exposure in Channa striatus ovary. Disruption of ooplasm, vacuolisation and edema were observed in oocytes. This study is also detected concentration dependent increase in the amount of atretic cells. In a study conducted by Han et al. (2011), effects of $\beta$ - endosulfan on the growth and reproduction of zebrafish were examined. They concluded that endosulfan exposure severely affects the reproductive function of zebrafish and the synthesis of vitellogenin in the liver. Likewise, in our study we proved that tribenuron methyl exposure inhibits and slows down oogenesis and cause severe histological alternations in the ovarian structure of zebrafish.

\section{References}

Annett, R., Habibi, H. R. and Hontela, A. 2014. Impact of glyphosate and glyphosate-based herbicides on the freshwater environment. J. Appl. Toxicol., 34(5): 458-479.

Baghfalaki, M., Shaluei, F., Hedayati, A., Jahanbakhshi, A. and Khalili, M. 2012. Acute toxicity assessment of tribenuronmethyl herbicide in silver carp (Hypophthalmicthys molitrix), common carp (Cyprinus carpio) and Caspian roach (Rutilus rutilus caspicus). Glob. Vet., 8: 280-284.

Daouk, T., Larcher, T., Roupsard, F., Lyphouta, L., Rigaud, C., Ledevin, M., Loizeau, V. and Cousin, X. 2011. Long-term food-exposure of zebrafish to PCB mixtures mimicking some environmental situations induces ovary pathology and impairs reproduction ability. Aquat. Toxicol., 105: 270-278.

De la Cruz, E., Bravo-Duran, V., Ramirez, F. and Castillo, L. E. 2014. Environmental hazards associated with pesticide import into Costa Rica, 1977-2009. J. Environ. Biol., 35: 43-55.

Duke, S. O. and Powles, S. B. 2008. Glyphosate: A once in a century herbicide. Pest. Manag. Sci., 64: 319-325.

Dutta, M. H. and Maxwell, L. B. 2003. Histological examination of sublethal effects of diazinon on ovary of bluegill, Lepomis macrochirus. Environ. Pollut., 121: 95-102.

Dutta, H. M. and Dalal, R. 2008. The effect of endosulfan on the ovary of bluegill sunfish: A histopathological study (Lepomis macrochirus). Int. J. Environ. Res., 2: 215-224. 
Gerber, R., Smit, N. J., Van Vuren, J. H. J., Nakayama, S. M. M., Yohannes, Y. B., Ikenaka, Y., Ishizuka, M. and Wepener, V. 2016. Bioaccumulation and human health risk assessment of DDT and other organochlorine pesticides in an apex aquatic predator from a premier conservation area. Sci. Total Environ., 550: 522-533.

Han, Z., Jiao, S., Kong, D., Shan, Z. and Zhang, X. 2011. Effects of B-endosulfan on the growth and reproduction of zebrafish (Danio rerio). Environ. Toxicol. Chem., 30: 25-31.

Li, K., Wu, J. Q., Jiang, L. L., Shen, L. Z., Ying Li, J., Heng He, Z., Wei, P., Lv, Z. and Fang He, M. 2017. Developmental toxicity of 2, 4-dichlorophenoxyacetic acid in zebrafish embryos. Chemosphere, 171: 40-48.

Louch, J., Tatum, V., Allen, G., Hale, V. C., McDonnell, J., Danehy, R. J. and Ice, G. 2016. Potential risks to freshwater aquatic organisms following a silvicultural application of herbicides in Oregon's coast range. Integr. Environ. Assess. Manag., 13(2): 396-409.

NCBI 2017. National Center for Biotechnology Information. PubChem Compound Database; CID=153909, https:// pubchem.ncbi.nlm.nih.gov/compound/153909 (Accessed 24 May, 2017).

Prato, E., Biandolino, F. and Scardicchio, C. 2006. Test for acute toxicity of copper, cadmium and mercury in five marine species. Turk. J. Zool., 30: 285-290.
Rzymski, P., Klimaszyk, P., Kubacki, T. and Poniedzialek, B. 2013. The effect of glyphosate-based herbicide on aquatic organisms - a case study. Limnol. Rev., 13(4): 215-220.

Saravanan, N., Uma, T. and Jothi Narendiran, N. 2016. Evaluate the effects of a pesticide synthetic pyrethroid to freshwater fish tissues of Esomus danricus (Ham.). Int. J. Zool. Appl. Biosci., 1(4): 191-197.

Sharma, S., Vyas, V., Tamot, S. and Jha, G. N. 2017. Effect of lead nitrate on the ovaries of the striped snakehead Channa striatus (Bloch, 1793). Indian J. Fish., 64(1): 98-100.

Szarek, J., Siwicki, A., Andrzejewska, A., Terech-Majewska, E. and Banaszkiewicz, T. 2000. Effects of the herbicide roundup on the ultrastructural pattern of hepatocytes in carp (Cyprinus carpio). Marine Environ. Res., 50: 263-266.

Tantarpale, V. T. and Rathod, S. H. 2014. Effect of cypermetherin on the ovary of freshwater fish Channa striatus. Indian J. L. Sci., 3(2): 87-89.

Wang, N. X., Tang, Q., Ai, G. M., Wang, Y. N., Wang, B. J., Zhao, Z. P. and Liu, S. J. 2012. Biodegradation of tribenuron methyl that is mediated by microbial acidohydrolysis at cell-soil interface. Chemosphere. 86(11): 1098-1105.

Yon, N. D., Olgun, U. and Akbulut, C. 2016. Ovarian follicle structure of zebrafish (Danio rerio Hamilton) after poly (2-ethyl-2-oxazoline) exposure. Indian J. Exp. Biol., 54: 829-834. 